\title{
Entidgeidungen dis
}

(Dber $=$ Seeants und der Seeämter dis

Deutithen Retdhs.

Liransgegebon

im

Reichsamt des Imtern.

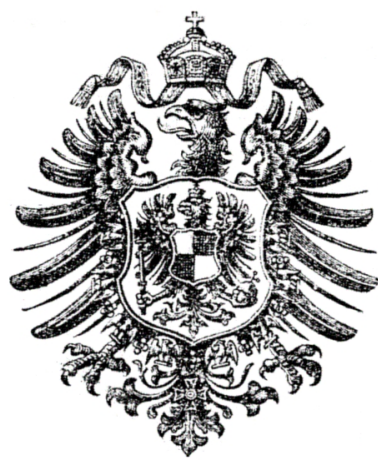

$\mathfrak{f} \mathfrak{u} \mathfrak{n} \mathfrak{f} \mathfrak{t} \mathfrak{x} \mathfrak{B}_{\mathfrak{a}} \mathfrak{n} \delta$.

1. Geft.

\section{Gantbirg.}

Drut und Derlag von $\mathbb{S}$ friederidfen \& $\mathbb{C}_{0}$. 1883. 